JOURNAL of

CONTEMPORARY INDONESIAN

ART

Jurusan Seni Murni

FSR ISI Yogyakarta

ISSN: 2442-3394

E-ISSN: 2442-3637

\section{EKSPLORASI MANDALA DALAM SENI DRAWING}

Oleh: Muhammad Khirzan Ulinnuha

Program Studi Penciptaan Seni, Program Pascasarjana

Institut Seni Indonesia Yogyakarta (ISI Yogyakarta)

J1. Suryodiningratan No. 8, Yogyakartaa 55143

email: khirzan.ulinnuha@gmail.com

\begin{abstract}
Abstrak
Penelitian ini merupakan pengamatan dan eksplorasi aspekaspek dalam mandala untuk dijadikan ide dalam menciptakan karya seni. Penelitian bertujuan menghasilkan karya seni yang inovatif dan eksploratif yang bisa memicu pentingnya menjaga pikiran serta hubungan antara manusia dan Penciptanya. Metode penelitian artistik ini adalah penelitian berbasis praktik. Peneliti menyatu dengan benda-benda yang diamati dengan imajinasi secara timbal-balik; serta merujuk pada metode kreasi yang diterbitkan dalam jurnal-jurnal untuk membuat penelitian yang bebas dari subjektivitas dan guna menghasilkan paparan yang lebih rinci. Hasilnya dalam bentuk beberapa karya seni sebagai representasi kreatifitas dalam mendefinisikan mandala dan filosofinya. Karya ini secara teknis merupakan hasil amatan atas berbagai referensi visual dan paduan berbagai teknik dan mendigitalisasi sebagai sentuhan akhir. Karya juga diterapkan dalam bentuk wallpaper gawai untuk menghadirkan makna baru atas mandala.

Kata kunci: Mandala, Praktik berbasis penelitian, Karya seni.
\end{abstract}

\section{Abstract}

This artistic research is an effort to observe and explore aspects in mandalas to be used as ideas in creating artwork. The purpose of this art creation research is to create innovative and exploratory works of art to spark the importance of taking care of our minds and maintaining the relationship between man and his Creator. This artistic research method is practice-based research. The researcher fused with objects observed by imagination reciprocally; he has also referred to the methods of published creations in current journals to make the research free from subjectivity and exposure is more detailed. The results are in the form of works art as representations of how the researcher creatively defines the mandala and the philosophy of mandalas. This work is technically the result of various visual references, blending techniques between Drawing-painting and digitization as the finishing touch. This work is also applied in the form of gadget wallpaper to present a new meaning over mandalas.

Keywords: Mandala, Research-based practice, Works of art 


\section{A. Pendahuluan}

Kesehatan mencakup keseluruhan, tidak hanya kesehatan tubuh secara fisik yang perlu dijaga, namun pikiran perlu kita jaga. Menjaga penting karena mempengaruhi kesehatan mental. Pikiran menjadi titik paling penting. Jika pikiran sakit, maka tubuh juga sakit. Mental pun turut sakit. Sebagai upaya untuk merawat pikiran, mengisi pikiran dengan hal-hal yang baik dan positif adalah salah satu caranya. Meski terdengar sangat klise, tapi keberadaan ajaran agama atau laku spiritual memang tidak dapat dipatahkan bahwasanya nilai dan ajaran tersebut akan membantu membentuk kehidupan menjadi lebih baik.

Mendekatkan diri kepada Sang Pencipta, atau setidaknya memahami dimana posisi manusia, adalah pemantik atas munculnya kesadaran akan ruang atas tempat manusia berada. Kesadaran ini akan membantu merawat pikiran. Serta mengontrol pikiran agar nafsu manusia tidak mengambil porsi lebih banyak sehingga setiap perilaku manusia senantiasa dekat dengan kebaikan dan bermanfaat.

Kebudayaan Asia, khususnya pada Buddhisme dan Hinduisme mengenal satu simbol yang yang di dalamnya terdapat banyak filosofi dan fungsi. Simbol tersebut adalah Mandala. Mandala adalah simbol berbentuk konfigurasi lingkaran geometris. Pada umumnya, mandala berfungsi sebagai medium, alat, "device", atau juga visual untuk menjelaskan dan menggambarkan bagaimana ajaran dan pesan-pesan dari tradisi-tradisi spiritual dapat dikomunikasikan dan dilaksanakan.

Mandala sebetulnya tidak hanya dimiliki oleh Asian Culture, Buddhisme dan Hinduisme, tapi juga di berbagai tempat dan ajaran yang lain di dunia. Suku asli amerika (native American) dan Suku maya juga memiliki mandala. Antara satu kebudayaan atau suku dengan yang lain, mereka memiliki pola, visual, dan makna yang berbeda-beda. Namun pada umumnya tetap sama, berfungsi sebagai bagian dari tradisi-tradisi spiritual.

Sebagai medium spiritual, mandala erat kaitannya dengan proses-proses yang membawa manusia untuk menyadari keberadaan manusia atas Penciptanya.
Mandala dalam konteks ini adalah sebagai ruang spiritual. Ruang dimana manusiadapat memahami posisi dirinya atas Penciptanya.

Salah satunya adalah seperti yang dicontohkan umat Buddha di Tibet. Mereka membuat Mandala dari lukisan pasir. Kegiatan melukis pasir tersebut adalah bagian tradisi spiritual. Di dalamnya terdapat proses-proses meditasi. Di dalam prosesnya pula mengandung banyak nilai dan filosofi yang syarat akan makna.

Dalam filosofi mandala, terdapat ajaran yang baik, pesan-pesan leluhur yang baik, dan nilai-nilai yang menunjukkan eksistensi manusia atas "ruang" tempat tinggalnya. Mengupas konsep mandala, menjadi upaya untuk memunculkan satu gagasan yang mampu memancing kesadaran manusia atas pentingnya menjaga ruang. Baik itu ruang secara fisik yaitu lingkungan, maupun ruang lingkungan di dalam pikiran.

Sebagai ide penciptaan karya, mandala dapat dari dikupas dari berbagai sisi. Mandala secara visual dengan bentuknya yang pada umumnya berupa lingkaran gemotris. Mandala secara mendalam yang mengandung nilai, filosofi, makna-makna. Mandala juga dapat dikupas dari sisi fungsinya dimana ia adalah medium spiritual.

Mandala berasal dari bahasa sansekerta yang artinya lingkaran. Mandala dapat pula dimaknai sebagai bentuk atau pola yang melingkar. Dalam bahasa inggris, Mandala dapat didefinisikan menggunakan tiga diksi yang berbeda, yaitu circle, orbs, dan sphere. Kesemuanya tetap merujuk pada bentuk lingkaran.

Buddha mengenal konsep karma dan reinkarnasi. Bahwasanya apa yang kita kerjakan di dunia atau kehidupan saat ini, akan menjadi konsekuensi di kehidupan selanjutnya. Begitu seterusnya. Kematian, hanyalah pintu menuju kehidupan selanjutnya. Sebuah konsep yang melingkar hasil pemaknaan atas definisi Mandala.

Banyak hal dapat dikupas dan dimaknai ulang dari konsep Mandala. Permasalahan permasalahan terkait Mandala dapat diamati lebih dalam. Apa yang ditemukan dari penelitian terkait 
mandala, dapat pula dikaitkan dengan kehidupan sehari-hari. Tentu dibutuhkan metode agar mandala dapat dikupas sedemikian rupa sehingga menjadi gagasan dalam kekaryaan yang dapat dijelaskan dan dipertanggungjawabkan dengan baik. Tidak hanya itu, perenungan, pengamatan dan pikiran-pikiran yang kritis juga sangat dibutuhkan untuk memunculkan visual dan bentuk karya yang baru dan berbeda.

Untuk menciptakan sebuah karya seni, diperlukan adanya kajian terkait pengetahuan seputar gagasan utama yaitu Mandala. Hal tersebut bertujuan untuk lebih memperkuat, mempertajam, dan memperdalam gagasan penciptaan. Pada akhirnya akan mempermudah kerangka berfikir dalam mencipta karya seni karena di dalam Mandala sendiri, terdapat banyak aspek yang dapat dikupas.

Pertanyaan pertama yang muncul tentu saja tentang arti Mandala. Apa itu Mandala? Mandala adalah simbol spiritual dan ritual. Secara visual, mandala berupa diagram yang merupakan konfigurasi simbol geometris yang difungsikan untuk hal-hal yang bersifat spiritual, sebagai sarana atau medium untuk ritual, dan visual untuk membantu menggambarkan bagaimana ajaran atau pesan dapat dikomunikasikan.

Secara definisi, kata Mandala diambil dari bahasa Sanskrit atau sansekerta yang berarti lingkaran (circle, orbs, sphere). Mandala juga dapat dimaknai sebagai bentuk atau pola yang melingkar, seperti bola atau bulatan. Simbol mandala, muncul di berbagai tempat. Meski mandala cukup identik dengan Buddhism, tapi tidak hanya umat Buddha saja yang memiliki simbol atau diagram melingkar yang serupa. Hinduism, Native American dan Mayan, juga memiliki mandala mereka sendiri.

Beberapa dari mereka juga memiliki fungsi yang kurang lebih hampir sama. Secara umum, mandala dipergunakan untuk kebutuhan spiritual dan ritual, serta sebagai visual yang menggambarkan ajaran-ajaran dari mereka. Tiap mandalamandala yang sudah ada merupakan bentuk ekspresi dan manifestasi atas keyakinan atau ajaran tertentu dari masing-masing daerah. Namun sebetulnya mandalamandala tersebut, meskipun berbeda satu dengan yang lain, cenderung memiliki satu kesamaan, yaitu nilai spiritual.

Berangkat dari beragamnya mandala, penulis mengklasifikasikan mandala untuk memudahkan penelitian penciptaan ini. Mandala dapat diklasifikasikan menjadi 3 garis besar, yang pertama adalah definisinya, kedua adalah filosofinya, dan ketiga adalah visualnya. Ketiga hal ini akan dapat dijadikan sumber untuk menciptakan karya seni.

Berikut ini adalah beberapa mandala yang tersebar di penjuru dunia yang penulis dapat dirangkum dari berbagai sumber.

a) Mandala Buddhism

Di Tibet, mandala dibuat menjadi sebuah lukisan pasir. Dimana mulai dari proses pembuatan sampai dibersihkan, adalah merupakan praktik- spiritual yang juga memiliki banyak filosofi. Geometri bentuk dalam simbol-simbol Mandala memiliki makna. Contohnya seperti bentuk lingkaran, menggambarkan tentang ketidakabadian dan hubungan atas segala hal (connectivity of all things). Bentuk persegi adalah gambaran waktu. Memulai dan berhenti, hidup dan mati, masa lalu dan masa depan, dan lain-lain.

Bentuk-bentuk Mandala Buddha sangat beragam. Mandala sangat kaya akan makna dan filosofi. Dia dapat menggambarkan atau mengilustrasikan berbagai macam hal.

Ada mandala yang menggambarkan bagaimana kehidupan sang Buddha. Ada mandala yang menggambarkan tentang tanah suci dan pencerahan tertinggi atau biasa disebut dengan "enlightment". Ada pula mandala yang menggambarkan tentang karma dan reinkarnasi.

Karma dan reinkarnasi juga merupakan satu gambaran mandala secara kontekstual. Umat Buddha meyakini bahwa kematian hanyalah jembatan menuju kehidupan selanjutnya. Karma adalah hukum sebab akibat. Apa yang manusia lakukan sekarang, akan menjadi konsekuensi di kehidupan selanjutnya. Hal tersebut menggambarkan 
pola berulang dan berkelanjutan seperti pola melingkar pada mandala.

Ajaran Buddha juga mengenal simbol bunga teratai, yang secara visual, apabila digambar dari atas, dia akan tampak seperti Mandala. Bunga teratai pada ajaran Buddha menggambarkan enlightenment. Secara simbolik digambarkan bagaimana bunga teratai tidak terkena lumpur atau tanah ketika berada di atas air. Tidak hanya pada ajaran Buddha, Bunga teratai juga memiliki nilai pada ajaran Hindu. Bagi mereka, bunga teratai dimaknai sebagai kesuburan atas jiwa manusia.

Figure 1. Tibetan Sand Painting Mandala,

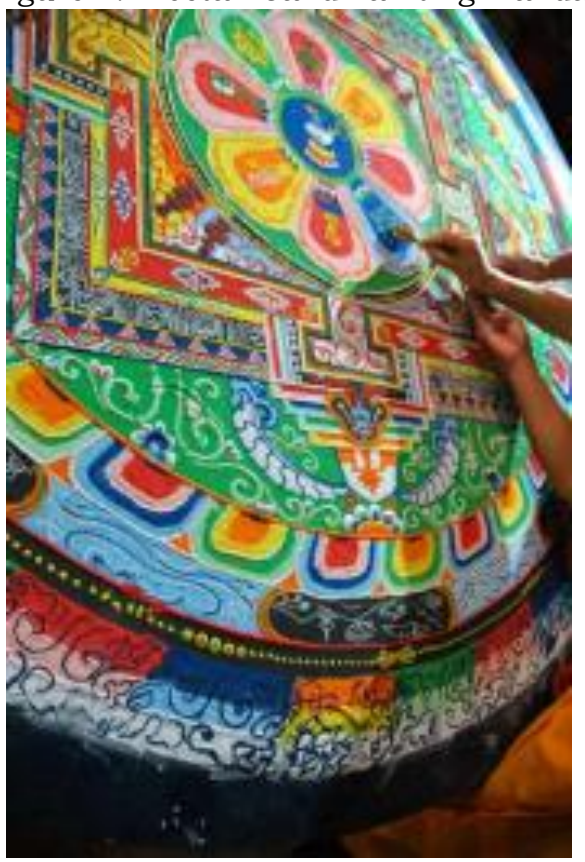

(Sumber:https://id.pinterest.com/pin/2251868543 $697895 /)$

b) Mandala Hinduism

Hinduism juga mengenal simbol yang mirip sekali dengan Mandala yaitu Yantra. Yantra berbentuk bujur sangkar dengan empat gerbang berisi lingkaran dengan titik atau bentuk lingkaran sebagai pusatnya. Secara umum, desain mandala Yantra selalu identik dengan bentuk geometris lingkaran yang simetris.

Mandala Yantra berfungsi sebagai simbol wahyu dari kebenaran kosmik dan sebagai bagan instruksi atau ajaran spiritual mengenai aspek pengalaman manusia. Mandala yantra juga berfungsi sebagai alat untuk memperlihatkan bagaimana semesta spiritual serta merepresentasikan lingkaran kehidupan dan eksistensi. Beberapa desain mandala yantra juga merupakan simbol atas dewa-dewa Hindu seperti Saraswati dan Ganesha.

Figure 2. Sri Yantra Mandala.

(Sumber:https://id.pinterest.com/pin/1122382157 01786240/)

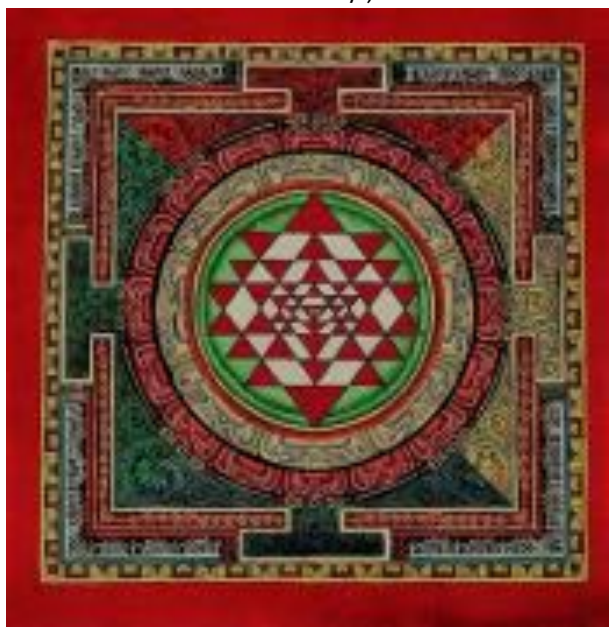

c) Mandala suku asli Amerika

Konsep religi masyarakat Amerika asli (native American) menggambarkan tentang persepsi dari realita. Mereka meyakini bahwa alam, tumbuhan, binatang, anak-anak, dan leluhur sudah lebih dulu terjalin di dunia roh sebelum mereka dilahirkan. Lingkaran mandala mereka merepresentasikan bulan dan matahari, proses terjadinya siang dan malam, arah mata angin, lingkaran kehidupan, kematian dan kelahiran kembali.

Masyarakat asli amerika mengenal yang namanya "Dreamcatcher". Sebuah artefak, kerajinan, jimat, sebagai bagian dari tradisi mereka. Berbentuk lingkaran kayu besar menyimbolkan lingkaran kehidupan. Lingkaran tersebut didekorasi dengan jaring-jaring, bulu, anak panah, 
batu mulia, dan manic-manik dimana kesemuanya memiliki filosogfi tertentu.

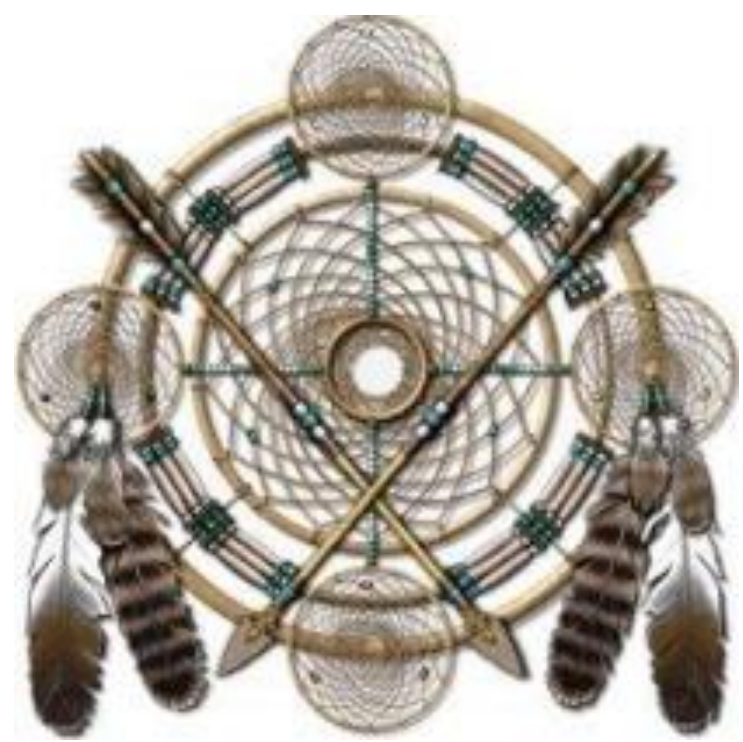

Figure 3. Native American dreamcatcher. (Sumber: pinterest.com)

d) Mandala Suku Maya

Suku maya memiliki simbol lingkaran geometris yang serupa yaitu kalender mereka yang dikenal sebagai Mayan Calendar atau Mayan Tzolkiin. Sistem kalender ini digunakan pada masa meso-amerika oleh para masyarakat di dataran tinggi Guatemala, Veracruz, Oaxaca, Chiapas dan Meksiko. Objek-obyek visual pada lingkaran tersebut menggambarkan tentang pergantian waktu seperti bulan-bulan pada kalender tahun Masehi namun dengan bahasa mereka sendiri.

Figure 4. Mayan Calendar. (Sumber:

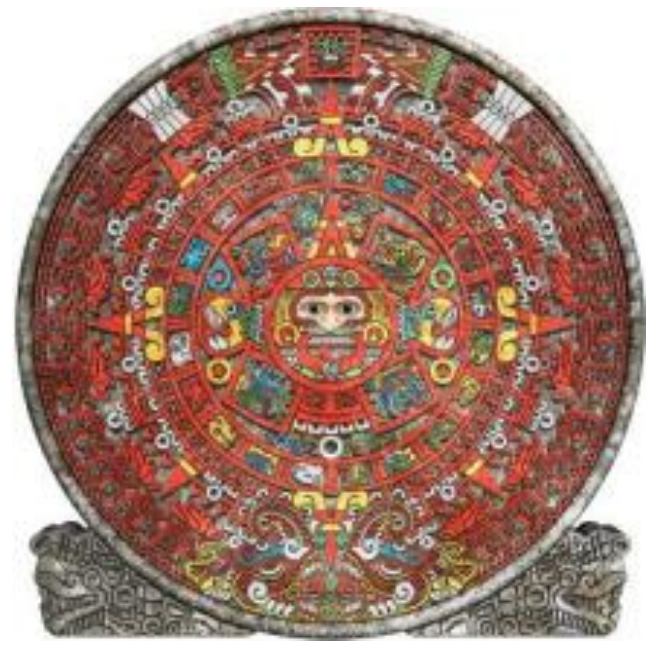

http://www.webexhibits.org/calendars/calendar mayan.html)

Dari beberapa gagasan dari mandala yang sudah ada tersebut, memunculkan upaya untuk menghadirkan satu gagasan karya. Karya tersebut diharapkan menjadi wacana pemantik kesadaran manusia atas pentingnya menjaga hubungan antara manusia dengan Penciptanya dimana hal tersebut secara tidak langsung juga akan mampu menjaga hati dan pikiran manusianya. Berdasarkan latar belakang tersebut, pertanyaan yang muncul sebagai rumusan masalah adalah:

- Bagaimana permasalahan terkait mandala dapat diwujudkan dalam karya seni?

- Bagaimana mentransformasikan permasalahan mandala menjadi ide karya seni?

- Bagaimana penelitian mandala dapat dikaitkan dengan konteks spiritual?.

- Bagaimana metafora ide bentuk mandala diwujudkan menjadi karya seni?

Tujuan penciptaan ini adalah yang pertama untuk menciptakan pemikiran baru atas mandala yang kemudian akan diwujudkan dalam karya seni. Kedua, memberikan informasi terkait mandala dalam konteks spiritual, dari sudut pandang praktik seni. Ketiga, adalah pemahaman hubungan seni dalam ranah sosio cultural dan spiritual.

Untuk mendapatkan ketajaman analisis dan inspirasi dalam penciptaan karya seni ini, disampaikan state of art permasalahan penciptaan karya meliputi seni Drawing dan aspek-aspek di dalam mandala, baik sebagai pendekatan teoritis maupun beberapa tinjauan karya terdahulu.

ini $\begin{aligned} & \text { Konsep penciptaan karya } \\ & \text { menggunakan lebih banyak }\end{aligned}$
menggunakan metafora. Pendekatan desain khususnya ilustrasi menjadi pilihan karena ilustrasi merupakan bahasa yang mudah dan relatif untuk cepat ditangkap oleh penonton.

Dalam era seni rupa kontemporer saat ini, pilihan luaran karya seni menjadi relative lebih bebas dan beragam, karena titik utamanya terletak pada gagasan yang disampaikan. Oleh sebab itu, karya seni yang bersifat ilustratif yang notabene adalah lingkup desain, dapat pula menjadi sebuah karya seni rupa. Seni dan desain tidak perlu dikelompokkan 
secara dikotomis. Menurut Donis A. Dondis (Marianto, 2019, hal. 26) pemahaman dan pendefinisian tentang seni di masa apa saja dalam faktor sejarah selalu bergeser dan berubah, namun faktor-faktor paling konstan dari diferensiasi itu adalah utilitas dan estetika.

Drawing menjadi pilihan utama dalam penciptaan karya-karya nantinya. Drawing memiliki nilai artistik yang kuat dimana setiap goresan yang dihasilkan akan dapat mewujudkan impresi dan nilai artistik tersendiri. Drawing di era kontemporer didefinisikan kembali dan didobrak batasbatasnya. Drawing

bukan sekedar catatan atau gambar coretcoret yang melulu hanya pensil di atas kertas. Dalam buku berjudul Vitamin D: New Perspective in Drawing (Dexter, 2005) Drawing didefinisikan sebagai proses pembuatan tanda yang digunakan untuk menghasilkan komposisi berbasis garis dengan jangkauan yang lebih luas. Mulai dari monumental hingga mikro, konseptual hingga 3 dimensi, dan dari hitam-putih hingga berwarna.

\section{B. Metodologi}

Penciptaan seni dalam proses ini menggunakan metode (Campbell, 1998) karena sudah terpublikasi sehingga validitasnya menjadi lebih kuat, dan proses pemaparannya juga lebih rinci. Metode David Campbell memiliki lima tahap yaitu preparation, incubation, illumination dan verification.

Tahap preparation adalah tahap meletakkan dasar. Mempelajari latar belakang dan seluk beluk aspek yang ada. Tahap concentration adalah tahap penalaran yang fokus mendalami permasalahan yang akan dihadapi. Tahap incubation adalah tahap perenungan, mengambil jarak dengan permasalahanpermasalahan yang dihadapi untuk mendapatkan kematangan maturasi spiritual. Tahap illumination adalah tahap pemecahan masalah dan pencapaian dalam merumuskan gagasan. Tahap verification adalah tahap implementasi kerja mulai dari tahap awal ide dasar hingga terwujudnya sebuah karya seni.

Sejalan dengan pelaksanaan metode David Campbell, untuk menghayati proses pembuatan karya seni dengan lebih kuat, digunakan pula metode practice based research atau penelitian artistik, yang dirujuk dari buku berjudul Artistic Research-theories, methods, practice, yang ditulis oleh Mika Hannula.

Metode practice based research tersebut memposisikan seniman tidak hanya menghadapi objek, tapi harus berada di dalam objek. Proses tersebut dapat dikatakan sebagai prinsip in and through, di dalam dan mengalami. Singkatnya, di dalam pelaksanaan metode David Campbell, metode practice based research berjalan berkelindan di dalamnya.

\section{Hasil dan pembahasan}

1) Tahap Preparation

Mandala cukup beragam baik dari segi visual maupun gagasannya. Oleh karena itu, dalam tahap ini terjadi proses in and through, yaitu proses keluar masuk untuk mencari ide dan gagasan. Proses in and through yang terjadi adalah ketika membuat mind map atau kerangka berpikir. Apa yang menjadi ruang lingkup dan batasannya, serta pendekatan apa yang perlu diperlukan untuk mengupas permasalahan mandala. Pendekatan desain menjadi pilihan karena mandala sejatinya adalah visual ilustrasi yang memiliki nilai fungsi secara visual. Bentuk desain salah satunya ilustrasi.

Ilustrasi dengan mengoptimalkan Drawing di dalamnya akan menghasilkan visual yang kuat dan mudah ditangkap untuk audience. Komposisi dan warna menjadi pertimbangan karena disesuaikan dengan segmen dan luaran visual yang akan dihasilkan.

2) Tahap Concentration

Pada tahap ini, penalaran sudah lebih terfokus. Hal tersebut dilakukan setelah mengobservasi dengan betul literatur yang ada serta karya-karya mandala terdahulu. Permasalahan terkait mandala dapat diklasifikasikan menjadi 2 gagasan utama. Yaitu secara tekstual (definisi) dan konseptual (filosofi).

Seperti yang sudah dijelaskan sebelumnya, definisi Mandala adalah lingkaran atau pola melingkar (orbs, circle, atau sphere). Secara makna denotasinya, maka segala hal yang serupa dengan lingkaran atau pola melingkar, sebetulnya dapat dikatakan sebagai pola mandala, seperti contohnya bunga atau kincir angin. 
Secara makna konotasinya, segala hal yang bersifat melingkar, seperti siklus terjadinya air hujan, juga dapat dikatakan sebagai pola mandala.

Mandala sangat kental dengan nilainilai spiritualnya. Mulai dari mandala yang dimiliki oleh kaum Buddha, Hindu, hingga Suku Maya, kesemuanya beririsan dengan nilai-nilai spiritual. Mandala juga dekat dengan nilai-nilai sosio kulturnya, yang menjelaskan bagaimana pola perilaku, adat istiadat, dunia lain, mitos dan lain-lain.

Beberapa filosofi mandala menggambarkan seperti pola reinkarnasi, konsep ruang dan waktu, past, present and future, serta menggambarkan hubungan antara manusia dengan Penciptanya.

3) Tahap Inkubasi

Untuk mencapai maturasi spiritual, menjaga jarak dan waktu terhadap persoalan objek menjadi satu hal yang perlu dilakukan. Proses in and through di dalam tahap incubation, berjalan bersama dengan proses perenungan dan diskusi-diskusi kepada para kolega yang memiliki minat dan wawasan yang sama terkait mandala.

Tahap ini adalah tahap berfikir yang diskontinu. Menurut (Goswami, 2014) Quantum of Creativity, proses kreatif muncul tidak linear melainkan diskontinu atau terputus-putus. Proses terputus-putus ini sejalan dengan prinsip in and through, di dalam dan mengalam, timbul dan tenggelam. Dalam tahap ini, akan muncul proses-proses evaluasi terhadap landasan dan perencanaan untuk ke depan.

4) Tahap Illumination

Tahap ini adalah tahap untuk mengidentifikasi dengan mengkonstruksi karya dari ide-ide yang sudah ditemukan. Di dalam tahap ini juga terjadi proses in and through. Tahap ini adalah tahap perancangan yang di dalamnya terdapat pemilihan metafora untuk memudahkan audience membaca karya. Mandala sendiri sudah memiliki filosofi yang cukup dalam. Pemaknaan ulang filosofi dari mandala terdahulu dapat dijadikan pijakan untuk memilih bahasa metafora pada karya seni yang akan diciptakan.

Di dalam tahap ini pula, pembuatan sketsa-sketsa dilakukan sebagai upaya untuk menangkap kilatan visual atas ide-ide yang sudah terbentuk. Seperti halnya pada perancangan desain, tahap sketsa adalah tahap yang penting. Seperti yang sudah dijelaskan pada tahap preparation, perwujudan penciptaan ini menggunakan pendekatan desain ilustrasi. Maka pada tahap illumination, pendekatan desain pada tahap ini memerlukan proses pengumpulan referensi atas karya-karya terdahulu dilakukan, untuk kemudian dijadikan acuan dan pertimbangan untuk membuat sketsa sketsa.

Pembuatan sketsa menggunakan prinsip in and through. Di dalam pembuatannya, akan terjadi proses mencoba-coba, mencari bentuk, mengurai ide-ide menjadi bentuk visual. Kegiatan membuat garis dan menghapus garis akan terjadi secara terus menerus. Pada proses kerjanya, akan membutuhkan lebih dari satu sketsa untuk pada akhirnya menjadi satu sketsa yang matang.

Dalam ajaran Buddha, lotus atau bunga teratai adalah bunga yang kerap kali muncul pada visual-visual mereka. Mandala pada umumnya berbentuk seperti bunga teratai. Dia seperti bentuk stilasi tampak atas dari bunga teratai. Lotus atau bunga teratai mengandung filosofi yang mencerminkan kejernihan dan ketulusan. Bunga teratai tumbuh di air. Bunganya mekar dengan tangkai panjang yang menjulang ke atas. Mencerminkan bagaimana bunga tersebut tetap murni dan karena tidak tersentuh air sama sekali. Beberapa literatur juga menyebutkan bahwa semakin keruh air di bawah bunga teratai, justru mekar bunga teratai justru akan semakin indah.

Karya ini mengolah definisi dan filosofi mandala. Karya ini merupakan pemaknaan ulang atas bunga teratai dan mandala. Gabungan konsep ritual doa dengan filosofi bunga teratai yang memiliki makna kejernihan. 


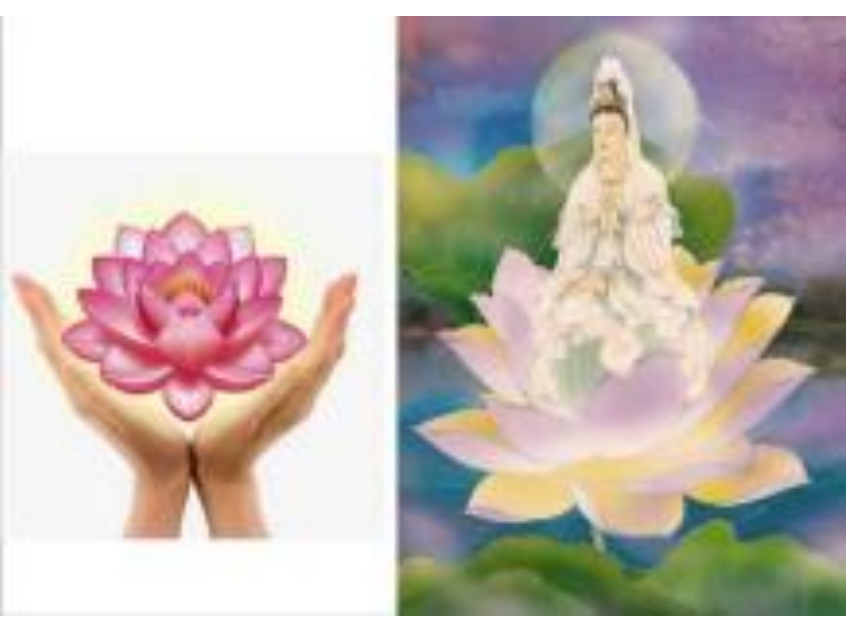

Figure 5. Referensi karya dengan tema bunga teratai dan doa. (Sumber: dokumen pribadi)
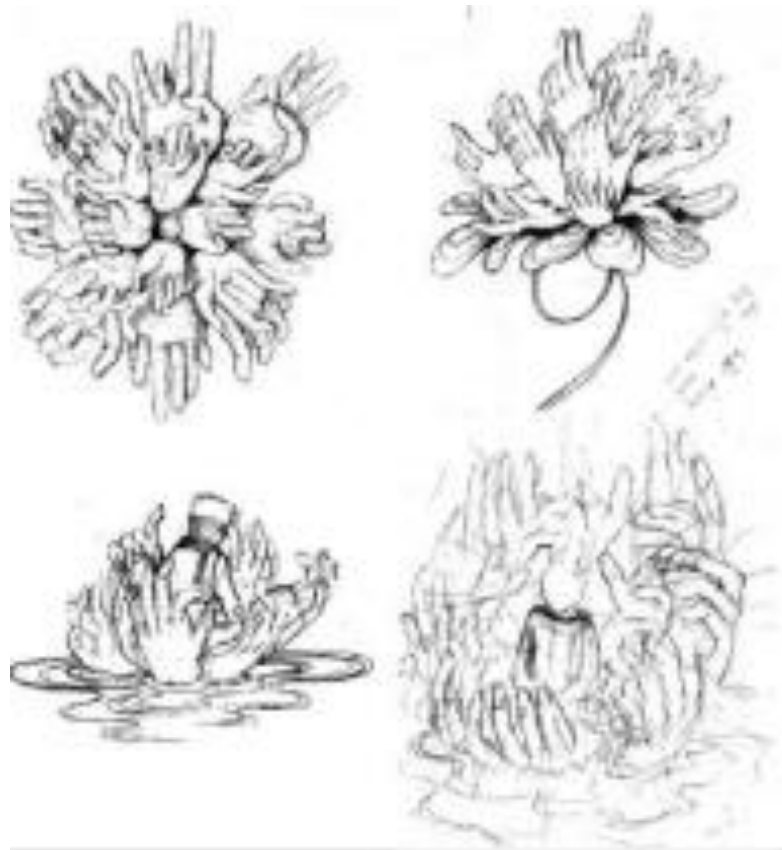

Figure 6. Sketsa karya dengan tema bunga teratai dan doa. (Sumber: dokumen pribadi)

5) Tahap Verification

Prinsip in and through terjadi saat pembuatan sketsa dan eksekusi akhir karya. Karya ini menggunakan medium tinta akrilik dan tinta cina di atas kertas Montval berukuran 75 x $95 \mathrm{~cm}$. Ketika keseluruhan karya sudah $80 \%$ selesai, terjadi pertimbangan artistik lain. Latar belakang terasa kosong, oleh sebab itu, tahap berikutnya adalah digitalisasi.

Proses digitalisasi dilakukan untuk memberikan tambahan visual di dalamnya. Font huruf arab bertuliskan doa qunut ditambahkan untuk memperkuat gagasan doa pada karya ini. Tulisan arab divisualkan seperti tulisan cina agar tetap selaras dengan latar belakang yang sudah dibuat.
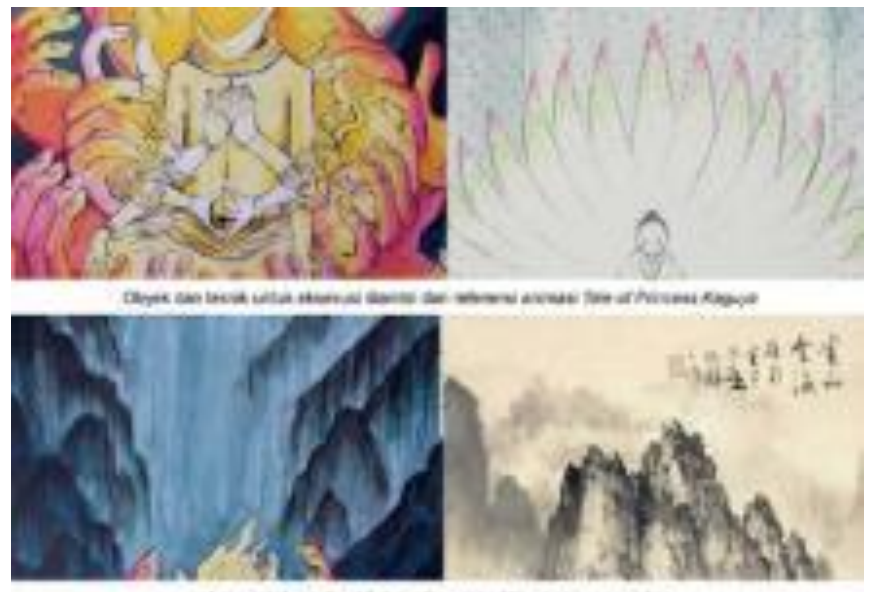

Figure 7. Implementasi referensi menjadi karya. (Sumber: dokumen pribadi)

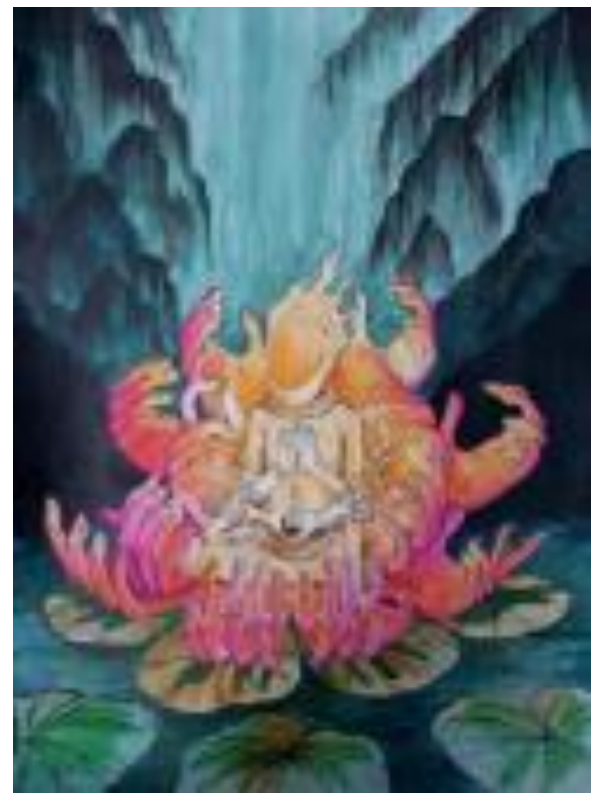

Figure 8. Karya jadi sebelum tahap digital (Sumber: dokumen pribadi) 


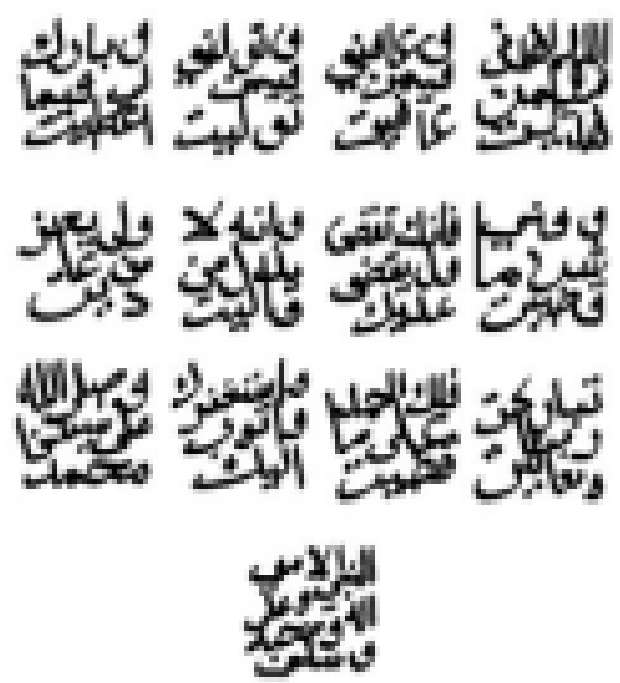

Figure 9. Konfigurasi tulisan arab doa qunut (Sumber: dokumen pribadi)

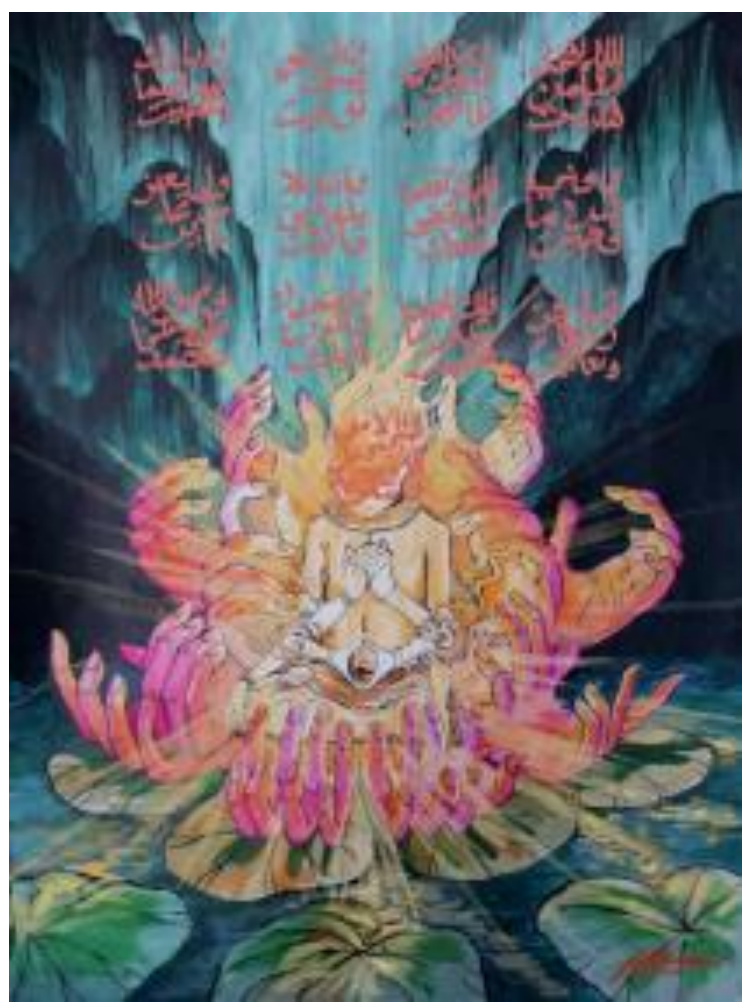

Figure 10. Karya akhir. Sumber: dokumen pribadi)

Masih pada prinsip in and through, pengembangan karya digital berlanjut menjadi wallpaper ponsel dengan pertimbangan fungsi mandala. Mandala berfungsi sebagai media spiritual. Sama halnya dengan karya ini, gawai dan wallpaper di dalamnya dimaknai ulang sebagai media spiritual di era saat ini. Maka luaran karya ini menjadi 3 item yang berbeda. Yang pertama adalah tinta dan akrilik di atas kertas montval berukuran $75 \times 95 \mathrm{~cm}$. Yang kedua adalah digital dengan ukuran 6496 x 8858 pixel dengan resolusi 300 dpi. Ketiga adalah pengaplikasian menjadi wallpaper ponsel dengan ukuran 1090 x 1920 pixel.

Figure 11. Mock up karya menjadi wallpaper

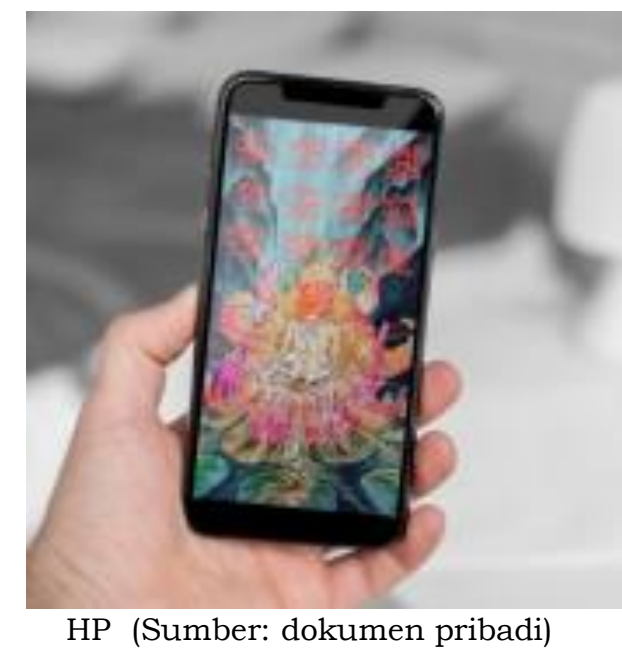

\section{Kesimpulan}

Mandala sudah tersebar di berbagai dunia dengan visual, nilai dan filosofinya masing masing tergantung dari mana dan oleh siapa dia dibuat. Gagasan mandala dipilih dengan pertimbangan sebagai wacana pemantik pentingnya merawat pikiran dengan cara menghadirkan nilainilai spiritual dalam kehidupan sehari hari dan menggambarkan bagaimana hubungan antara manusia dengan Penciptanya.

Mandala yang sudah ada dimaknai kembali untuk kemudian mampu menghadirkan karya-karya baru. Pemaknaan ulang dan eksplorasi yang dilakukan adalah terkait definisi dan filosofi mandala. Hal tersebut menandakan adanya temuan atau capaian yang sudah dilakukan penulis dalam rangka mengembangkan atau melakukan inovasi terhadap karya-karya penulis sebelumnya.

Terlepas dari aspek visual yang sudah dihasilkan serta temuan eksplorasi mendalam terkait permasalahan mandala, satu hal yang penting untuk digaris bawahi adalah proses kerja dan perumusan penciptaan ini. Penciptaan ini menggunakan metode David Campbell yang sistematis yaitu preparation, 
concentration, incubation, illumination, dan verification. Serta menggunakan metode "Research in the art" atau dikenal sebagai prinsip in and through dari Mika Hannula (Hannula et al., 2005).

Prinsip in and through bertujuan untuk mendalami proses, menghayatinya lebih dalam, menghadirkan pengalaman mengalami, dan serta menunjukkan bahwasanya penelitian seni juga dapat dijelaskan secara sistematis dan ilmiah. Oleh sebab itu, apa didapatkan adalah sebuah metode dan proses penciptaan yang dapat menunjang terciptanya karya seni yang eksploratif dan inovatif.

\section{E. Kepustakaan}

Campbell, D. (1998). Mengembangkan Kreativitas, terjemaahan. Manhunghardjana. Yogyakarta: Kanisius.

Dexter, E. (2005). Vitamin D: new perspectives in drawing. Phaidon London.

Goswami, A. (2014). Quantum creativity: Think quantum, be creative. Hay House Incorporated.

Hannula, M., Suoranta, J., \& Vadén, T. (2005). Artistic Research. Theories, Methods and Practices.

Marianto, M. D. (2019). Seni dan Daya Hidup Dalam Perspektif Quantum. Scritto books \& BP ISI Yogyakarta.

Laman:

"What is a Mandala? History, Symbolism, and Uses". invaluable.com. 19 Desember 2018.

https://www.invaluable.com/blog/what-isa mandala/ "About the Mandala-Its meaning, design and colouring. indimode.com. 13 November 2017.

https://indimode.com/blogs/news/designi ng-the-mandala-and-itsmeaning "Mandala diagram". britannica.com. 30 Mei 2019.

https://www.britannica.com/topic/mandal a diagram "Meaning of Mandalas". onetrribeapparel.com. 17 October 2019. https://www.onetribeapparel.co $\mathrm{m} /$ blogs / pai / mandala-meaning

"Sand Mandala in Tibet and Its Profound Philosophy". tibettravel.com. 15 November 2019. https://www.tibettravel.org/tibetan arts/sand-mandala.html

"Mandala". wikipedia.com. 22 April 2021. https://en.wikipedia.org/wiki/ Mandala

Art Home School, 2019. Mandala History (video).

Youtube. https://youtu.be/bub4PlADG7M leighjmccloskey, 2018. THE ART \& HEALING POWER OF THE MANDALA with LEIGH J MCCLOSKEY. (Video). Youtube. https://www.youtube.com/ watch?v=CQOW QrH-vGs HVHS Art, 2021.

History of Mandala. (Video). YOutube. https://youtu.be/PJBt96Fa0rM 